\title{
Modelling Lippia spread down flooding river systems.
}

\author{
$\begin{array}{lll}\text { S. Barry } & \text { R. Hickson } & \\ & \text { K. Stokes } & \\ & \end{array}$
}

(Received 25 July 2007; revised 10 January 2008)

\begin{abstract}
Lippia (Phyla canescens) is an invasive, non-native plant prevalent in the Australian Murray-Darling river system that is considered detrimental in terms of lost agricultural production and environmental damage. This weed predominantly spreads as clonal fragments during floods and its growth rate is strongly related to soil moisture content. We use stage structured integro-difference equations to model the dispersal of reproductive units (clonal fragments and seeds) and explore the effects of flood length and height on spatial spread rates of the weed.
\end{abstract}

\section{Contents}

1 Introduction

See http://anziamj.austms.org.au/ojs/index.php/ANZIAMJ/article/view/314 for this article, (C) Austral. Mathematical Soc. 2008. Published January 15, 2008. ISSN 1446-8735 
3 Results

4 Conclusion

\section{Introduction}

Ecological invasions by non-native plant species damage ecosystem functioning and reduce agricultural productivity, leading to expensive control programs to sustain production. Lippia (Phyla canescens) is a prostrate perennial plant endemic to South America which has invaded parts of the MurrayDarling river system in Eastern Australia in the last fifty years, although the source of the weed is unknown. The weed has two methods of reproducing: clonal reproduction occurs via re-rooting of detached plant fragments, usually during flood events along rivers leading to explosive growth of new colonies [1] when flood waters recede; and a slower sexual reproduction through seeds. Economic losses due to Lippia are estimated [1] at a conservative $\$ 38$ million per annum for stock loss in the Murray-Darling system, $\$ 1800$ million for total environmental damage since introduction (erosion, biodiversity loss), and continuing control costs of roughly $\$ 100$ per hectare. An aim of this study is to investigate the effect of climate change [2] on weed spread, by considering how length and magnitude of flood events [3, 4], induced by climate change, affect weed distribution along rivers.

Numerous models of weed spread exist $[5,6,7]$ involving reaction diffusion equations, integro-difference equations, matrix models, and cellular automata models [8]. We model Lippia spread using a stage structured, integro-difference model, with the species divided into three life-cycle stages: seed producing adult plants, seedlings, and seeds which accumulate in a 
seed bank. Plant fragments are spread down the river with an exponential distribution [9], and seeds are scattered radially using a mixed exponential/Gaussian distribution including long distance dispersal. The model contains numerous parameters governing growth rates, dispersal proportions, distances and terrain height. We do not attempt to analyse the effect of every parameter but instead keep most parameters constant using available experimental data $[10,11]$, and vary only the flood length and flood height - key parameters influenced by climate change. Whereas previous studies looked at spreading weeds, there have been no studies on the effect of flood duration and intensity on the weed propagation, particularly when the weed species has a growth rate strongly dependent on water level, as is the case here. For simplicity we choose a uniform terrain with a linear terrain profile and a single river extending through the centre of the domain as shown in Figure 1. While we can simulate spread on real terrains and rivers, this preliminary study is focused on exploring the approximate behaviour of flood induced spread, without complications from the variabilities of real terrains, and is unique in considering the interaction of flood induced spread and terrain.

\section{The model}

Under future climate change the frequency and intensity of extreme flood events in Australia is predicted to change [3]. Here we investigate the effect of these two parameters on Lippia spread, whose main spread mechanism is via flooding. Obtaining a better understanding of the relationship between spread rate and flood intensity will allow better resource use in containing potential outbreaks.

A key parameter affecting Lippia performance is the dependence of growth rate on moisture level in relation to the soil surface $[12,13]$. Combining experimental results $[14,15]$ a growth rate is found as a function of water depth as indicated in Figure 2. We reasonably extend the quadratic relationship to 


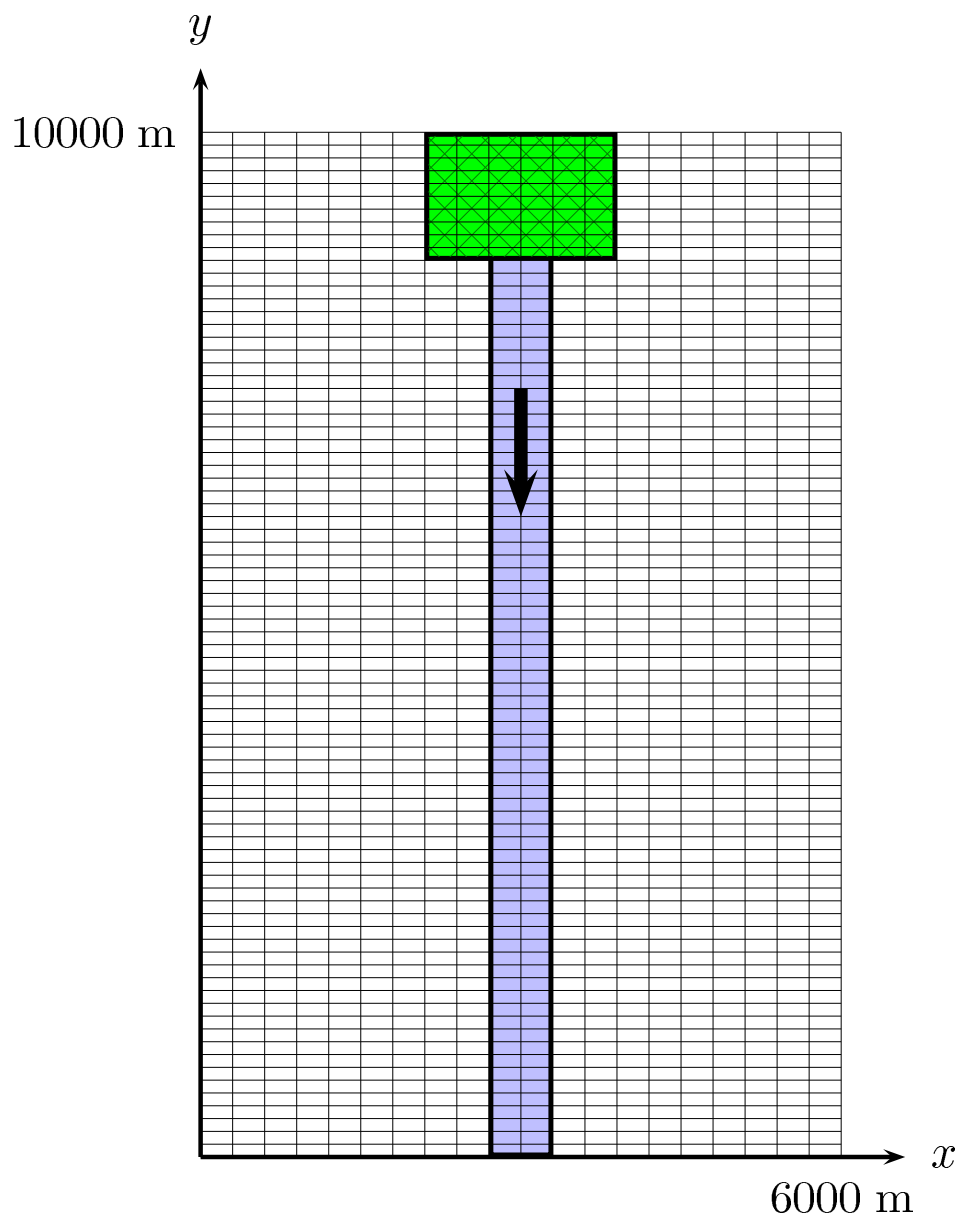

Figure 1: Schematic of weed spread down a simulated river system. Weeds initially occur at the top of the river, which flows from top to bottom. The finite discretisation and scale of the region is also shown. 


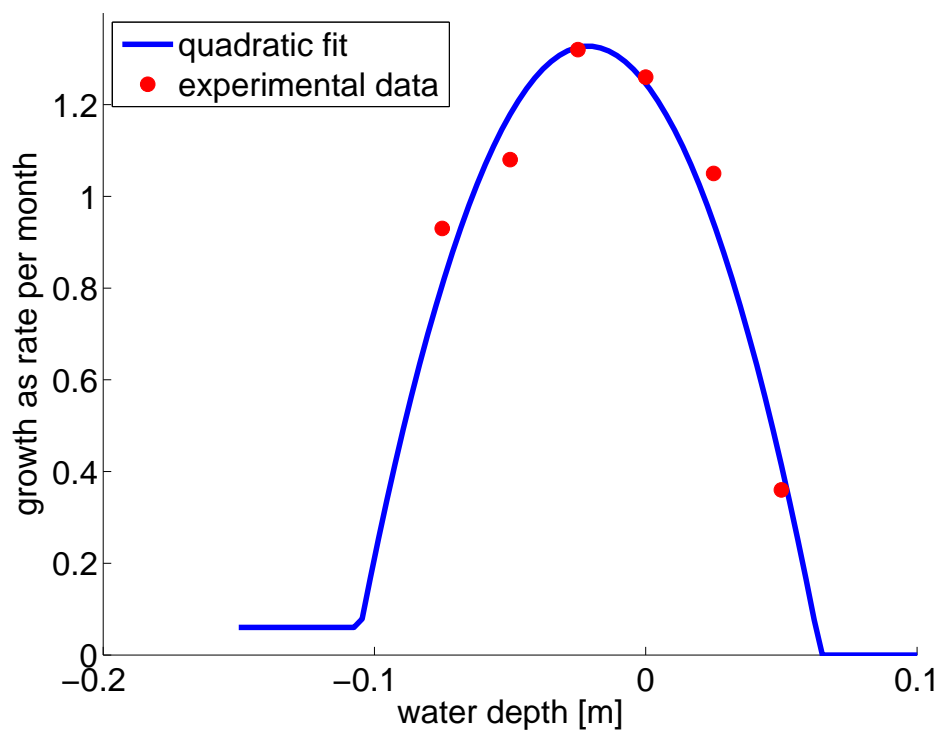

FigURE 2: Lippia growth rate as a function of water depth showing data and quadratic regression fit $g=1.2463-0.0076 W-0.00018 W^{2}$ with $R^{2}=98.12 \%$ and a $\chi^{2}=.00056<\chi_{.95}^{2}=5.99$ indicating a good fit to the data.

include a small growth rate under dry conditions - when there is a small level of plant growth dependent on base rainfall levels [10, 11], and a zero growth rate for high water levels, when the depth of water effectively drowns the plants. During severe drought conditions, growth rates would drop to zero. Negative water depth indicates water level below the soil surface. Where possible other parameters are derived from limited empirical data [10, 11] although some parameters were estimated to give realistic results where data was unavailable. Our aim is not to give exact predictions for weed spread, but to investigate qualitative overall behaviour for the spread of weeds with reasonably physical properties similar to Lippia.

The density of Lippia, denoted by $N_{1}(x, y, t)$, is measured as the number of branches per square metre, $\left[\mathrm{br} / \mathrm{m}^{2}\right]$, with these being re-dispersed along 
the river using an exponential dispersal kernel [4]:

$$
N_{1}^{*}(x, y, t)=\int_{s} K_{1}\left(s-s^{\prime}\right) N_{1}\left(x^{\prime}, y^{\prime}, t-d t\right) d s^{\prime},
$$

where $x, y$ is the spatial position, $s \equiv(x, y)$ and $s^{\prime} \equiv\left(x^{\prime}, y^{\prime}\right)$ are distances along the river, and $d t$ is the time discretisation. The dispersal kernel is a decaying exponential distribution [9],

$$
K_{1}(r)=\frac{1}{r_{0}} e^{-s / s_{0}},
$$

with $s$ the distance along the river, $s_{0}$ is assumed a linear function of the flood strength so that dispersal speed ranges from $700 \mathrm{~m} / \mathrm{month}$ for no flood up to $1700 \mathrm{~m} / \mathrm{month}$ for a flood of height $5 \mathrm{~m}$. These values are estimates only as little experimental data is currently available. During a flood, fragments are spread evenly across the river. Seeds, denoted $N_{2}(x, y, t)\left[\mathrm{sd} / \mathrm{m}^{2} / \mathrm{month}\right]$, are produced according to

$$
N_{2}(x, y, t+d t)=\frac{2 c_{1} N_{1}^{*}(x, y, t)}{1+N_{1}^{*}(x, y, t) / N_{m}},
$$

with $c_{1} \approx 100$ seeds/month/branch assumed constant and $N_{m}=20 \mathrm{br} / \mathrm{m}^{2}$ the carrying capacity. This expression for $N_{2}$ was chosen since for $N_{1}^{*} \rightarrow 0$, $N_{2} \rightarrow 2 c_{1} N_{1}^{*}$, seed production is proportional to number of branches, but as $N_{1}^{*} \rightarrow N_{m}$ then $N_{2} \rightarrow c_{1} N_{m}$; that is, there is not a linear increase in seed production per plant density when the plants reach carrying capacity due to a reduction in available resources to the plant. These seeds, $N_{3}$, are distributed by a two-dimensional dispersal kernel $K_{2}(d r)$ :

$$
N_{3}(x, y, t)=\int_{y^{\prime}} \int_{x^{\prime}} K_{2}(d r) N_{2}\left(x^{\prime}, y^{\prime}, t\right) d x^{\prime} d y^{\prime},
$$

where $d r \equiv \sqrt{\left(x-x^{\prime}\right)^{2}+\left(y-y^{\prime}\right)^{2}}$ is the distance between the plant and the seed deposition point. The kernel is a mix of local Gaussian dispersal, 
a long-tailed exponential dispersal, and a delta function representing seeds which simply fall beneath the plant $[16,17]$. Hence

$$
K_{2}(d r)=\frac{1}{r_{1}} c_{2} \exp \left(-d r / r_{1}\right)+c_{3} \frac{1}{\pi r_{2}^{2}} \exp \left(-d r^{2} / r_{2}^{2}\right)+c_{4} \delta(d r),
$$

where $r_{1}=400 \mathrm{~m}$ is the typical distance seeds travel by exponential dispersal, $r_{2}=80 \mathrm{~m}$ the typical distance spread by Gaussian dispersal, and $c_{2}=0.4$, $c_{3}=0.1$ and $c_{4}=0.5$ are the proportions of seeds in each type of dispersal. These dispersed seeds are added to a seed bank, $N_{4}(x, y, t)$ [seeds $\left./ \mathrm{m}^{2}\right]$ :

$$
\frac{\partial N_{4}}{\partial t}=-c_{5} N_{4}+N_{3}-c_{6} N_{4}
$$

where $c_{5}=0.2 \mathrm{month}^{-1}$ represents a death rate of the seeds in the bank, the $N_{3}$ term represents new seeds being deposited, $c_{6}=0.02$ month $^{-1}$ represents seeds which germinate into seedlings during a flood and we estimate $c_{6}=$ 0.005 month $^{-1}$ to represent seed germination rate without a flood. The number of seedlings

$$
N_{5}(x, y, t)=c_{6} N_{4}\left(x, y, t-d t_{1}\right),
$$

where $d t_{1}=1$ month is the time taken for seeds to germinate into seedlings. The death rate and maturation rate of seedlings is, for simplicity, factored into the constant $c_{6}$. The equation for mature plants, which die and grow according to commonly used logistic laws, is

$$
\frac{\partial N_{1}^{*}}{\partial t}(x, y, t)=\left[c_{9}-c_{10} N_{1}^{*}(x, y, t)+N_{5}\left(x, y, t-d t_{2}\right)\right]\left(1-\frac{N_{1}^{*}(x, y, t)}{N_{m}}\right),
$$

where $N_{m} \approx 20$ branches $/ \mathrm{m}^{2}$ is the maximum carrying capacity of the plant, $c_{9} \in[0,1.4]$ month $^{-1}$ is the growth rate which varies with water level (Figure 2), $c_{10}=0.02$ month $^{-1}$ is the death rate and $d t_{2}=1$ month is the time delay for seedlings to mature into seeds.

All the constants $c_{1}$ to $c_{10}$ may vary in space and time although for simplicity all are taken as constant apart from the growth rate $c_{9}$ which 


\section{TABLE 1: Summary of parameters.}

\begin{tabular}{crll} 
par. & value & units & description \\
\hline$c_{1}$ & 100 & seeds/month/branch & seed production \\
$c_{2}$ & 0.4 & proportion & seeds dispersed exponentially \\
$c_{3}$ & 0.1 & proportion & seeds dispersed as Gaussian \\
$c_{4}$ & 0.5 & proportion $^{-1}$ & seeds not dispersed \\
$c_{5}$ & 0.2 & month $^{-1}$ & seed bank death rate \\
$c_{6}$ & $0.0005-0.02$ & month $^{-1}$ & seed germination rate \\
$c_{9}$ & $0-1.4$ & month $^{-1}$ & plant growth rate \\
$c_{10}$ & 0.02 & month $^{-1}$ & plant death rate \\
$N_{m}$ & 20 & ${\text { branches } / \mathrm{m}^{2}}^{2}$ & plant carrying capacity \\
$d t_{1}$ & 1 & month & seed germination time \\
$r_{1}$ & 400 & metres & exponential seed dispersal \\
$r_{2}$ & 80 & metres & Gaussian seed dispersal
\end{tabular}

is strongly dependent on water depth and has the quadratic form shown in Figure 2, and $c_{6}$ which has different values during flood events. In Table 1 the various parameters are summarised. This exploratory work is designed not to accurately measure Lippia spread for a given region, but to give indications of the approximate behaviour of species spread which can then be used to refine experimental data collection. A more complete study, including parameter sensitivity analysis and direct application to regions with full experimental data, is the subject of further research.

A flood is modelled by considering a terrain which rises uniformly as shown in Figure 3. Shown on this figure is the base river height of 0.5 metres, and a typical flood height of 2 metres. For simplicity, during a flood the river is assumed to rise and fall quadratically as shown in Figure 4, although simulations show the precise form for this rise and fall is not critical.

The numerical simulation here assumes an area of $[6000,10000]$ metres in 
the $[x, y]$ directions discretised to $[20,80]$ grid points. This is illustrated in Figure 1 and is seen in Figure 5(a). The river runs in the $y$ direction with the an initial distribution of plants at one end, $N_{1}=10$ branches $/ \mathrm{m}^{2}$ over an area of $2.1 \times 10^{6}$ metres $^{2}$ along the river. Time is discretised weekly and simulations run for 100 weeks. All floods begin in week 8 and have a length ranging from zero to 20 weeks. Flood height is varied from zero to 4.5 metres above normal river level. The simulation evaluates the number of plants in each grid at each time step (usually one week). Weeds and seeds are dispersed according to the rules outlined earlier, with river dispersal occurring before seed dispersal. The system is then time-stepped until termination. The simulation is part of a larger package, PlantSim [8] we developed to simulate weed spread in a variety of terrain using any number of different simulation options. The routines were tested for time and space accuracy, against known exact solutions, and for self consistency by comparing different simulation options.

\section{$3 \quad$ Results}

Figure 5 shows plant mass contours for a typical simulation (flood height of $1.5 \mathrm{~m}$, flood length of 14 weeks). Figure 5 a shows the initial plant mass with the river running vertically down through the centre of the plants. Figures $5 \mathrm{~b}$ and $5 \mathrm{c}$ show times $t=7$ and $t=19$ weeks respectively, when the fragments have started moving down the river and then when the flood has begun, spreading plants laterally across the river, but also drowning plants in the centre. This leads to a concentration of plants on the edges of the river. However, as the flood recedes, the exposed water-saturated land promotes a large growth of plants which then rapidly reach carrying capacity and spread down the river as fragments, as shown in Figure $5 \mathrm{~d}$ at $t=43$ weeks.

The total plant mass for floods of length between 0 and 30 weeks and constant height $2 \mathrm{~m}$ is shown in Figure 6. Initially there is an exponential 


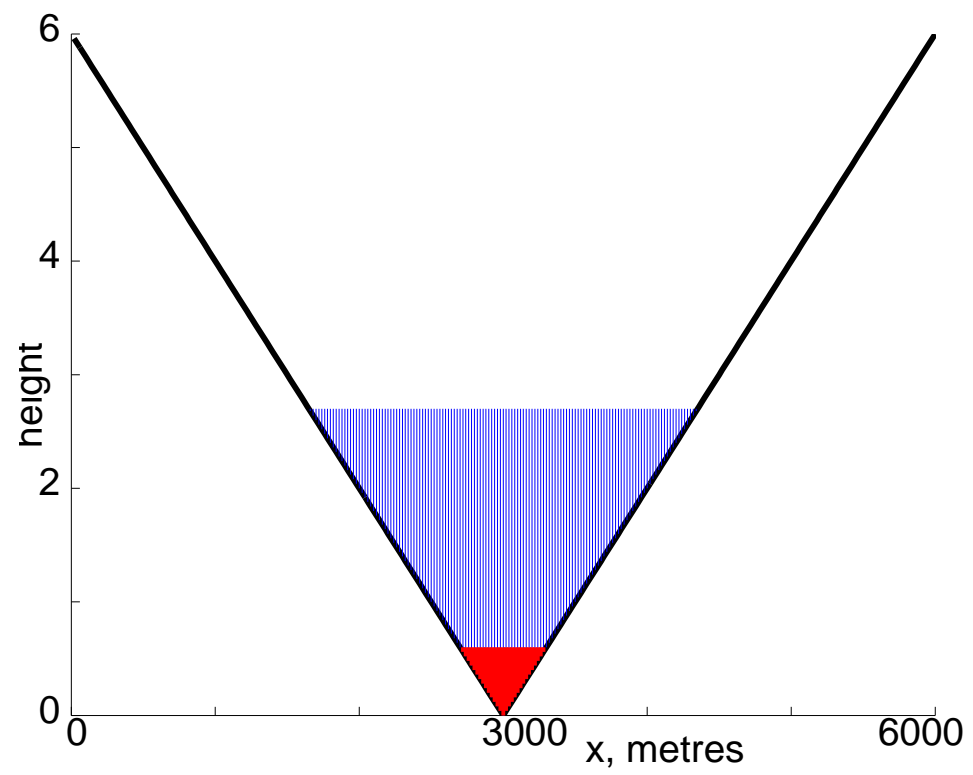

FiguRE 3: Illustration of river height profile, in metres, with a the base water level and flood level indicated by shaded regions.

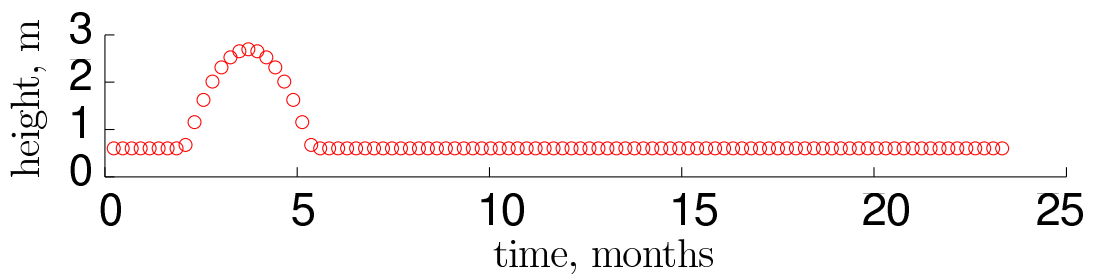

Figure 4: Typical flood height above zero, in metres, as a function of time in months. 


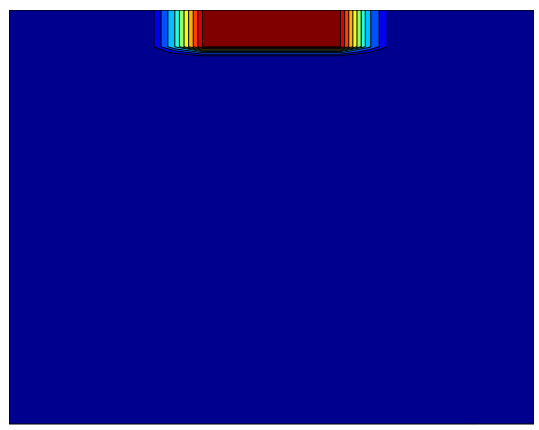

(a)

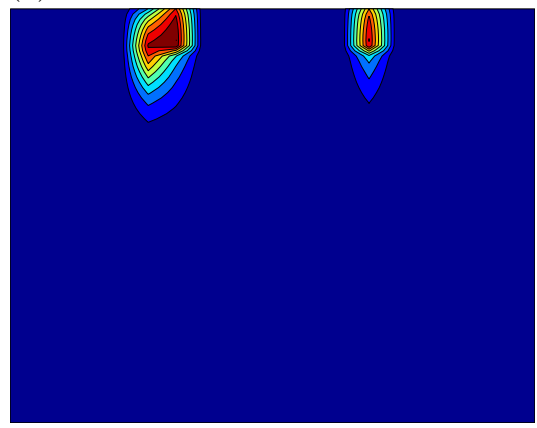

(c)

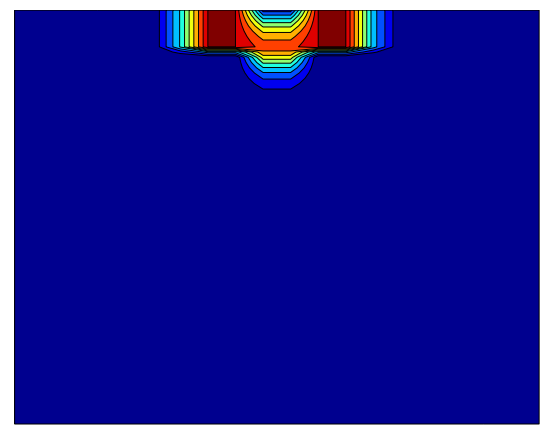

(b)

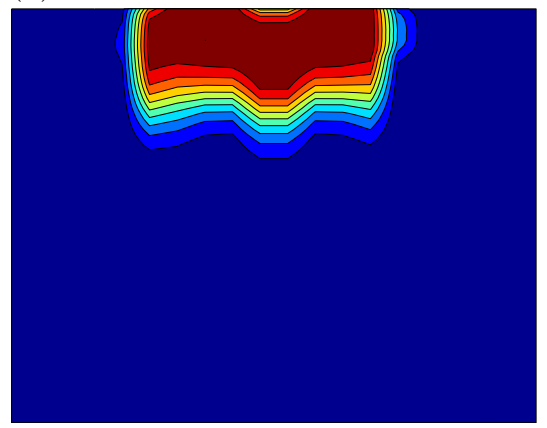

(d)

Figure 5: Contours of plant density at four different times. (a) Initial plant distribution. (b) 7 weeks: river re-depositing plants. (c) 19 weeks: flood drowning plants. (d) 43 weeks, flood complete and river re-depositing plants. 


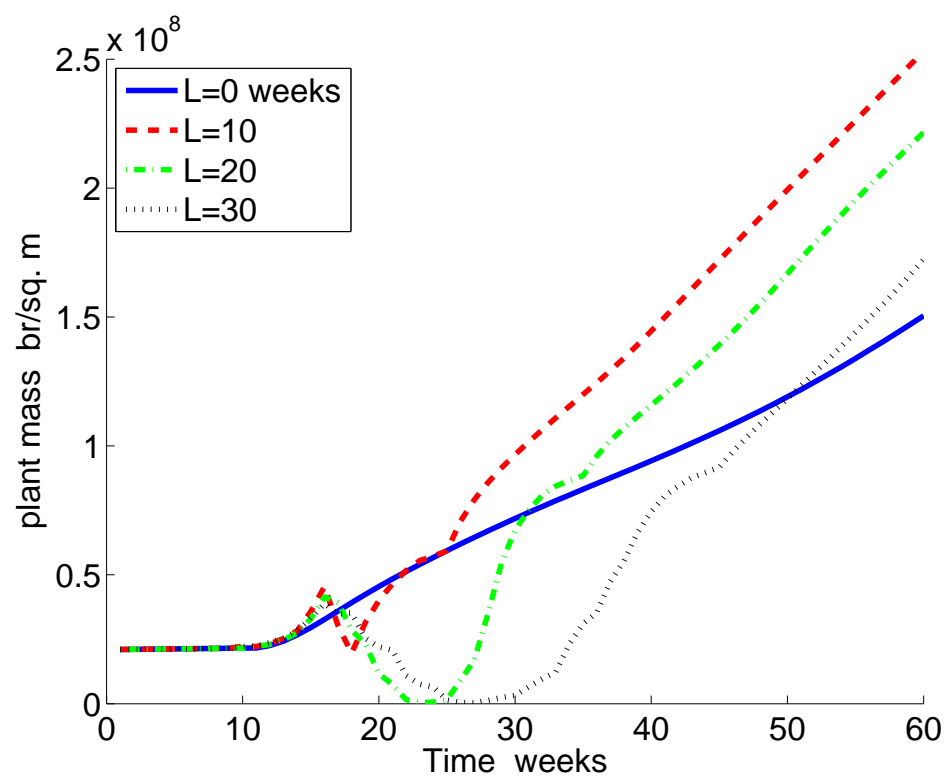

Figure 6: Plant mass as a function of time for different flood lengths $L$ [weeks].

rise as plants grow and then spread. The flood then kills off a number of plants due to the high death rate when plants are over-submerged. However, after the flood has subsided there is an almost linear rise in plant mass as the plant spreads down the river at near saturation level. As expected the no-flood case has a different behaviour since the flood spreads and saturates the region, allowing plants to reach carrying capacity in the region around the river.

During a flood there are competing influences: a flood propagates and spread the weed; but too long or high a flood and weeds are drowned. In Figure 7 the total plant mass at time $t=100$ weeks (after the floods have finished) versus the two main parameters of flood length and height are shown. The results indicate that there is an optimal length (13 weeks) where 


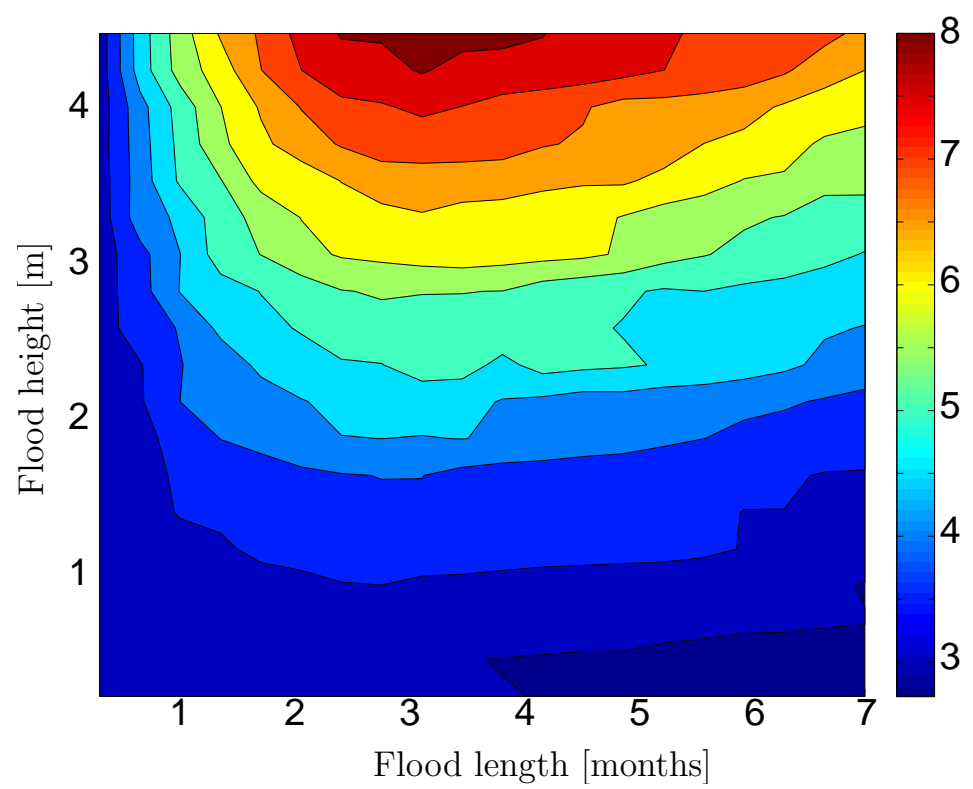

Figure 7: Contours of total plant mass $\left[\mathrm{br} / \mathrm{m}^{2}\right]$ at time 100 weeks, as a function of flood length and flood height. The maximum occurs when flood length is approximately 3.2 months and increases with flood height.

the flood propagates the weed, and that plant spread increases with flood height.

\section{Conclusion}

We investigated the effect of flood length and height on the spread of an invasive weed, choosing parameters typical of Lippia spread in the MurrayDarling system. Floods, while helping to propagate the plants, can also drown them, and these competing effects give an optimal flood length for maximum spread. Even a small flood can greatly increase the spread of the 
weed, and give rise to vastly different behaviour to that of a no-flood case. Further work will continue to refine data collection, prior to conducting a sensitivity analysis of all parameters to explore interactive behaviours within the system. While accurate predictive results are not possible, given the lack of data in which to assign parameter values, general trends have been identified which will be further explored both numerically and experimentally.

Acknowledgements Part of this work was supported by the Australian Greenhouse Office. Roslyn Hickson is supported by a scholarship from the School of Physical, Environmental and Mathematical Sciences, UNSW at ADFA. The assistance of Drs Geoffry Mercer and Harvinder Sidhu is appreciated.

\section{References}

[1] J. Earl, The distribution and impact of Lippia (Phyla canescens) in the Murray Darling system. Agricultural Information and Monitoring Services report for the Lippia Working Group, 2003. http://www. cotton.crc.org.au/Publicat/Weeds/index.htm C360

[2] K. Hennessy, K. McInnes, D. Abbs, R. Jones, J. Bathols, R. Suppiah, J. Ricketts, T. Rafter, D. Collins, D. Jones, Climate change in New South Wales, Part 2: Projected changes in climate extremes, CSIRO Consultancy Report for NSW Greenhouse Office, 2004. C360

[3] R. Suppiah, K. J. Hennessy, Trends in total rainfall, heavy rain events and number of dry days in Australia, 1910-1990. International Journal of Climatology, 18, 1141-1164, 1998. doi:0.1002/(SICI)10970088(199808)18:10¡1141::AID-JOC286¿3.0.CO;2-P C360, C361 
[4] A-M. Truscott, C. Soulsby, C. F. Palmer, L. Newell, P. E. Hulme, The dispersal characteristics of the invasive plant Mimulus guttatus and the ecological significance of increased occurrence of high-flow events. J. Ecology, 94, 1080-1091, 2006. doi:10.1111/j.1365-2745.2006.01171.x C360, C364

[5] A. Hastings, Models of spatial spread: is the theory complete? Ecology, 77(6), 1675-1679, 1996. http://www. jstor.org/view/00129658/di986021/98p0171i/0 C360

[6] S. I. Higgins, D. M. Richardson, A review of models of alien plant spread. Ecological Modelling, 87, 249-265, 1996. doi:0304-3800(95)00022-4 C360

[7] M. Kot, Elements of Mathematical Ecology, Cambridge University Press, 2001. C360

[8] R. Hickson, S. I. Barry, K. Stokes, Comparison of weed spread models, ANZIAM J(E), 49, C324-C340, 2008; in Proceedings of the 8th Biennial Engineering Mathematics and Applications Conference, EMAC-200\%, Eds. Geoffry N. Mercer and A. J. Roberts. http://anziamj . austms.org.au/ojs/index.php/ANZIAMJ/article/ view/339 C360, C367

[9] T. Riis, K. Sand-Jensen, Dispersal of plant fragments in small streams, Freshwater Biology, 51, 274-286, 2005. doi:10.1111/j.1365-2427.2005.01496.x C361, C364

[10] M. Macdonald, W. Whalley, B. Sindel, M. Julien, J. Duggin, Flood induced recruitment of Lippia. In: B. Hackney, K. Bailes, J. Pilz, H. Burns (Eds) Proceedings of the 21st Annual Conference of The Grassland Society of NSW, Wagga Wagga, NSW, 135-136, 2006. C361, $\mathrm{C} 363$ 
[11] M. Macdonald, The ecology of Lippia (Phyla canescens). PhD Thesis, The University of New England, Armidale, NSW, Australia, 2007. C361, C363

[12] C. W. P. M. Blom, Adaptations to flooding stress: from plant community to molecule. Plant Biology, 1, 261-273, 1999. doi:10.1055/s-2007-978515 C361

[13] R. McCosker, Lippia (Phyla nodiflora): An invasive plant of floodplain ecosystems in the Murray-Darling Basin. A report on the distribution and ecology of Lippia in the lower Gwydir Valley and the Murray Darling Basin prepared for the Gingham Watercourse Landcare Group. University of New England, Australia, 1994. C361

[14] A. Hobson, Invasive weeds: a threat to wetland ecosystems. Honours Thesis, University of New England, Armidale, NSW, Australia, 1999. C361

[15] B. Taylor, G. C. Ganf, Comparative ecology of two co-occurring floodplain plants: the native Sporobolus mitchellii and the exotic Phyla canescens. Marine and Freshwater Research, 56, 431-440., 2005 doi:10.1071/MF04196 C361

[16] M. A. Lewis, S. Pacala, Modelling and analysis of stochastic invasion processes, J. Math. Biology, 41, 387-429, 2000. doi:10.1007/s002850000050 C365

[17] F. Lutscher, A short note on short dispersal events, Bull. Math. Biology, 69, 1615-1630, 2007. doi:10.1007/s11538-006-9182-9 C365 


\section{Author addresses}

1. S. Barry, School Physical, Environmental \& Mathematical Sciences, University of New South Wales at ADFA, Canberra, Australia. mailto:s. barry@adfa.edu.au

2. R. Hickson, School Physical, Environmental \& Mathematical Sciences, University of New South Wales at ADFA, Canberra, Australia.

3. K. Stokes, CSIRO Division of Entomology, Canberra, ACT, Australia. 